\title{
Influence of impulse waveshape on breakdown voltage of a nonuniform-field gap in compressed gases
}

\author{
K. Natarajan, M.E., and G. R. Govinda Raju, B.E., Ph.D., C.Eng., M.I.E.E.
}

\author{
Indexing term: Breakdown
}

\begin{abstract}
Investigations were made into the influence of the impulse waveshapes, gas pressure $p$ and polarity on the breakdown voltage $V_{s}$ of a sphere-plane gap in compressed air and nitrogen. The pressure was varied from $0 \mathrm{lbf} / \mathrm{in}^{2}$ gauge to $150 \mathrm{lbf} / \mathrm{in}^{2}$ gauge, the gap spacings from $6.35 \mathrm{~mm}$ to $102 \mathrm{~mm}$ and the risetimes of the impulse voltages from $2 \cdot 1 \mu \mathrm{s}$ to $189 \mu \mathrm{s}$. For an impulse voltage of either polarity, certain gap lengths exhibited a critical-pressure effect, and the gap lengths and pressure at which this effect was observed depended on the risetime of the impulse voltage. Observations of the dependence of $V_{s}$ on the risetime showed that $V_{s}$ decreased with increasing risetimes, for risetimes of $16 \mu \mathrm{s}$ or $40 \mu \mathrm{s}$, beyond which it increased again to reach a maximum at risetimes of the order of $100 \mu \mathrm{s}$. For risetimes longer than $100 \mu \mathrm{s}, V_{s}$ again decreased with increasing risetime. This behaviour was similar for both nitrogen and air. Possible mechanisms are suggested to explain this behaviour.
\end{abstract}

\section{Introduction}

It is well known that the impulse breakdown voltage $V_{s}$ of a nonuniform field gap such as exists between a point and a plane is higher than that for steady-state voltage. While considerable data are available on $V_{s}$ for steady-state voltage, particularly in uniform electric fields, ${ }^{1,2}$ very few investigations have been made into the influence of the impulse waveshape on $V_{s}$ in compressed gases. The earlier measurements of $\mathrm{McConnell}^{3}$ in compressed air were confined to a single waveshape, $1.5 \times 50 \mu \mathrm{s}$, while the data of Crouch and Whitman ${ }^{4}$ were obtained in nitrogen at atmospheric pressure. The voltages used in their investigation had risetimes of $0 \cdot 5-550 \mu \mathrm{s}$, and the time taken to reach $50 \%$ of the crest on a tail of a wave was $10-9000 \mu \mathrm{s}$.

For a nonuniform-field electrode configuration, $V_{s}$ does not increase with pressure continually. A peak in the breakdown voltage/pressure characteristics ( $V_{s}$ against $p$ ) has been observed at a pressure $p_{m}$, and, for higher pressures up to a critical pressure $p_{c}, V_{s}$ decreased. For pressures beyond $p_{c}$, $V_{s}$ increased again. This effect was known as the "criticalpressure effect', and was reported only for a positive polarity voltage. ${ }^{5-7}$ Recently, Govinda Raju and Lakshminarasimha ${ }^{8}$ have confirmed, in compressed air, the earlier results of Steiniger, ${ }^{9}$ who showed that, in sulphur hexafluoride, the critical-pressure effect occurred both for positive and negative polarity voltages. Lakshminarasimha and Govinda Raju ${ }^{10}$ have reported on the dependence of $V_{s}$ of a point-plane gap on the impulse risetime in compressed air.

Because of our interest in compressed gases as a possible insulating medium, we have measured the impulse-breakdown voltage of compressed air and nitrogen and investigated the influence of the impulse waveshape, gas pressure and polarity on $V_{s}$. The waveshapes used had risetimes of $2 \cdot 1-$ $189 \mu \mathrm{s}(1.67 \times$ the time required to rise from $30 \%$ to $90 \%$ of peak value), and the time taken to decline to half the crest value was in the range of $1000 \mu \mathrm{s}(+10 \%)$. Sphere-plane gaps with a high-voltage sphere of $11 \mathrm{~mm}$ diameter and a plane of $230 \mathrm{~mm}$ diameter having a Rogowski profile were studied at gap spacings in the range of $6 \cdot 36-102 \mathrm{~mm}$. The pressure was varied from $0 \mathrm{lbf} / \mathrm{in}^{2}$ gauge to $150 \mathrm{lbf} / \mathrm{in}^{2}$ gauge. Before admitting the gases into the pressure vessel, they were dried by a column of calcium hydroxide, and, as an additional precaution, a thick layer of silica gel was spread on the floor of the compressed-gas chamber. The-highest voltage used, which was only limited by the high-voltage bushing of the experimental chamber, was $300 \mathrm{kV}$, and this voltage was derived by a Marx-type impulse generator. The waveshape

Paper 6563 S, first received 18th May 1970 and in revised form 17th Paper $6563 \mathrm{~S}$

Mr. Natarajan is with the Visveswarayya College of Engineering, Mr. Natarajan is with the Visveswarayya College of Engineering, Bangalore University, Bangalore-1, India, and Dr. Govinda Raju is
with the Department of High Voltage Engineering, Indian Institute of Science, Bangalore-12, India

PROC. IEE, Vol. 118, No. 12, DECEMBER 1971 of the voltage was varied by the standard technique of varying the circuit parameters of the impulse generator. Details of the experiment are given elsewhere.*

\section{Breakdown voltages}

\subsection{Sphere-plane gaps with positive-polarity impulse}

The determination of the $50 \%$ breakdown voltage was tedious because of a considerable conditioning effect: Such conditioning behaviour has been observed by several workers with steady-state voltages. Frequently, there were instances when a higher voltage caused a smaller percentage of breakdowns than a lower voltage. This was attributed to the insufficient conditioning of the electrodes and the inherently statistical nature of breakdown. An attempt to determine the number of impulses that were required to give a reasonably good accuracy in determining the $50 \%$ breakdown voltage proved too laborious. Therefore, it was decided to check whether ten impulses at each voltage level were sufficient by adopting the following procedure. Ten sets of ten impulses per set were applied at a constant voltage. For each set and for the ten sets as a whole, the percentage breakdown was calculated. Fig. 1 shows the plots of percentage breakdown against impulse-set number for a given pressure and gap setting. The breakdown percentage did not differ by more than $20 \%$ between individual sets in almost all the cases (Fig. 1a). This procedure, when repeated over several spacings and pressures, led to the following conclusions: (a) for a given spacing and pressure, the variation in percentage breakdown between individual sets decreased with increase in voltage, $(b)$ for a given pressure, and with a voltage causing approximately $50 \%$ breakdown, the variation in percentage breakdown between individual sets increased with the increase in gap distance, $(c)$ for a given gap distance, and with a voltage causing approximately $50 \%$ breakdown, the variation in breakdown percentage between individual sets decreased with increasing pressure, and $(d)$ the conditioning effect did not show any consistent dependence on the impulse waveshape. Consequently, it was decided to apply between 50 100 conditioning pulses (sometimes 200 pulses), at the end of which, consistent dependence of the percentage breakdown on the applied voltage was obtained. Then, ten pulses were applied at each voltage level, and the $50 \% V_{s}$ was determined in the usual way, by determining the percentage breakdown at each voltage level. The absolute accuracy of voltage measurement is within $\pm 5 \%$, but the relative accuracy is better than this, within $\pm 2 \%$.

Fig. 2 shows the $V_{s}-p$ curves for $2 \cdot 1 \times 1000 \mu$ s positivepolarity impulses at various constant gap spacings. The

* Natarajan, K.: 'Switching surge breakdown of a sphere-plane gap in compressed air and nitrogen', M.E. thesis (unpublished), Indian Institute of Science, Bangalore, 1969 
critical-pressure effect was observed for $6.36 \mathrm{~mm}, 12.7 \mathrm{~mm}$ and $25.4 \mathrm{~mm}$ (not included in the Figure) gaps. For larger gap lengths of $38 \mathrm{~mm}$ and $51 \mathrm{~mm}$, the critical-pressure effect disappeared completely, and $V_{s}$ increased with $p$ continually. This was unexpected. When the gap length was increased still further, to $76 \mathrm{~mm}$, there was some evidence for the critical-pressure effect, but this was not considered to be conclusive. However, at $102 \mathrm{~mm}$ gap length, the effect was pronounced. From Fig. 2, the $V_{s} / p$ curve for each gap length may be classified into one of three groups; (a) at certain gap lengths, the critical-pressure effect is very clearly seen, as for $6 \cdot 35,12 \cdot 7,25 \cdot 4$ and $102 \mathrm{~mm}$ gaps, (b) gaps at which the critical-pressure effect disappeared and $V_{s}$ increased monotonically with $p$, as at $38 \mathrm{~mm}$ and $51 \mathrm{~mm}$, or (c) gaps which showed an intermediate behaviour, that is, there is some, but not conclusive, evidence for the criticalpressure effect. This type of behaviour is seen for the $76 \mathrm{~mm}$ gap. $V_{s} / p$ curves obtained at other waveshapes confirmed that this classification is generally valid. We suggest that the behaviours $(a)$ and $(b)$ are associated with different mechanisms of breakdown, and the behaviour under $(c)$ represents an intermediate stage between the two mechanisms. Fig. 3 shows the $V_{s} / p$ curves for $189 / 1100 \mu$ s impulses, and Table 1 gives a summary of the results.

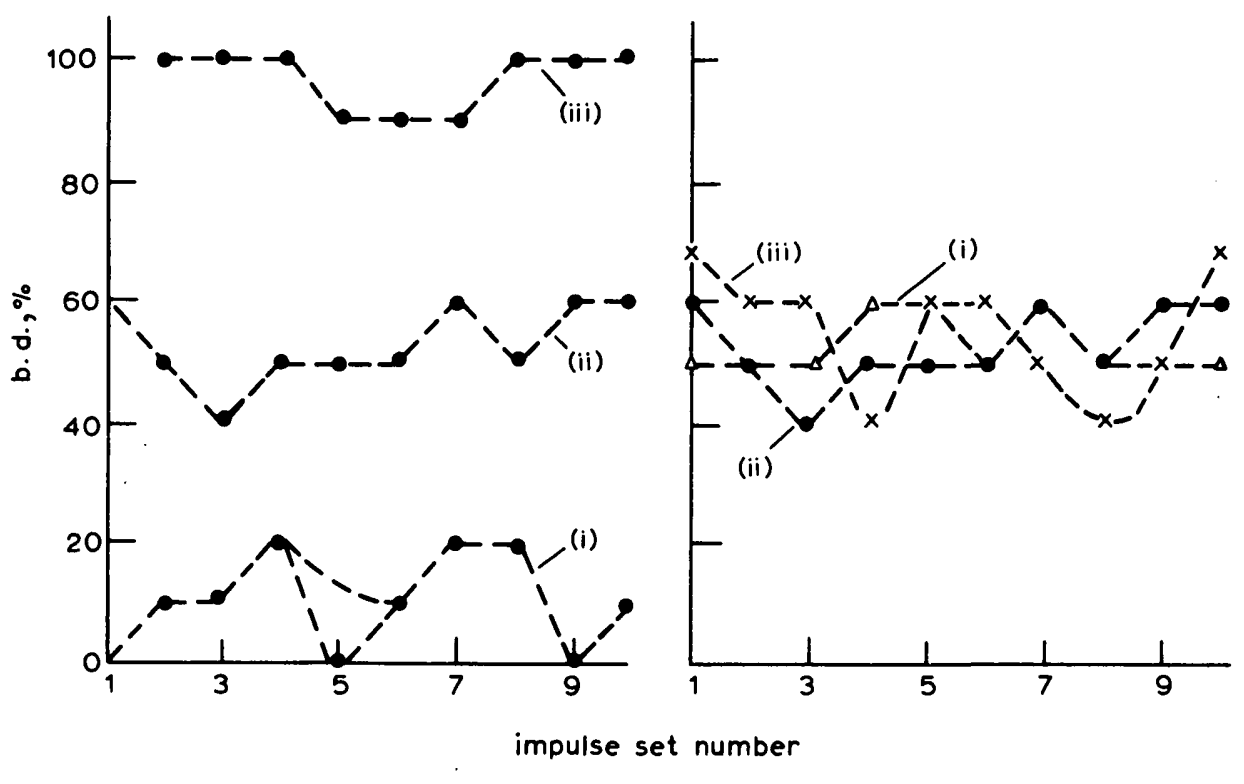

Fig. 1

Percentage breakdown as a function of impulse set number

(a) Curves (i), (ii) and (iii) are for successively higher voltages at $50 \mathrm{lbf} / \mathrm{in}^{2}$ gauge pressure and $25.4 \mathrm{~mm}$ gap length (b) (i) $6.35 \mathrm{~mm}$ gap length, $70 \mathrm{kV}$; (ii) $25 \cdot 4 \mathrm{~mm}, 85 \mathrm{kV}$; (iii) $51 \mathrm{~mm}$ at $120 \mathrm{kV}$ at $50 \mathrm{lbf} / \mathrm{in}^{2}$ gauge pressure

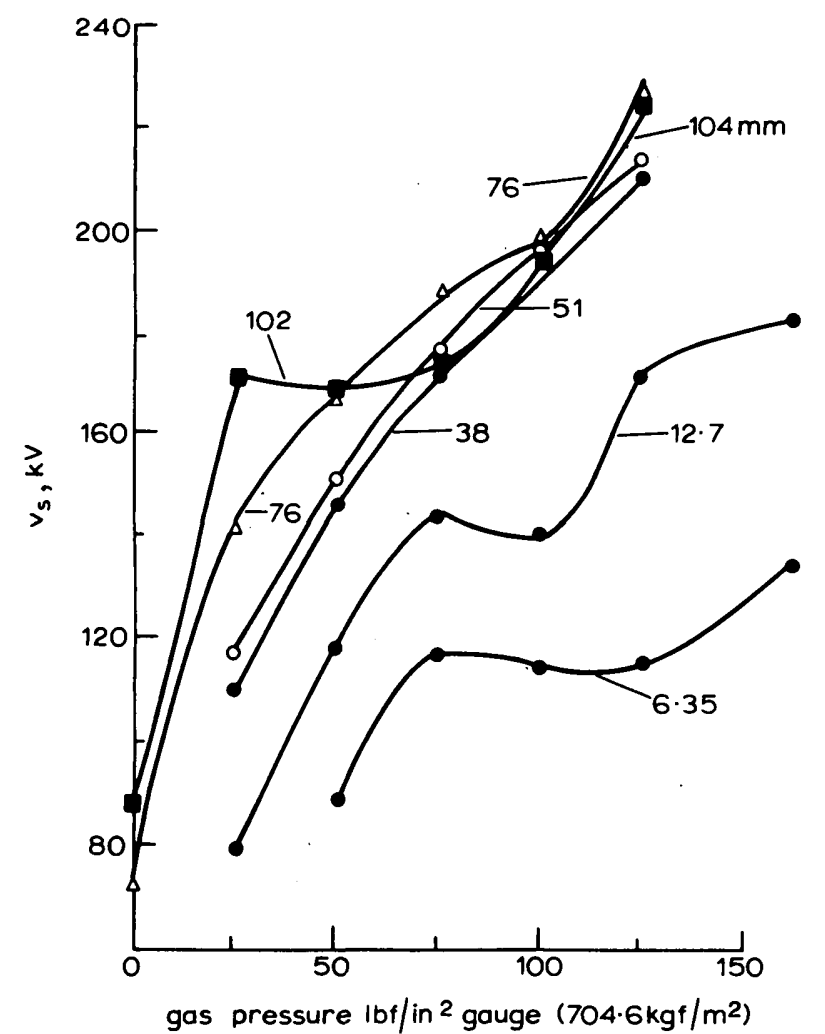

Fig. 2

$50 \% V_{s} / p$ curves in compressed air at various spacings for $2 \cdot 1 / 1000 \mu$ s positive-polarity impulse
Table 1

\begin{tabular}{|c|c|c|c|c|}
\hline \multirow{2}{*}{$\begin{array}{l}\text { Impulse } \\
\text { risetime }\end{array}$} & \multirow{2}{*}{$\begin{array}{l}\text { Gap lengths } \\
\text { investigated }\end{array}$} & \multicolumn{3}{|c|}{ Gap lengths showing mechanisms } \\
\hline & & $a$ & $b$ & c \\
\hline$\mu \mathrm{s}$ & $\mathrm{mm}$ & $\mathrm{mm}$ & $\mathrm{mm}$ & $\mathrm{mm}$ \\
\hline $2 \cdot 1$ & $\begin{array}{l}6 \cdot 35,12 \cdot 7, \\
25 \cdot 4,38, \\
51,76,102\end{array}$ & $\begin{array}{l}6 \cdot 35,12 \cdot 7 \\
25 \cdot 4,102\end{array}$ & 38,51 & 76 \\
\hline $16 \cdot 0$ & $\begin{array}{l}6.35,12 \cdot 7, \\
25 \cdot 4,38, \\
51,76,102\end{array}$ & $\begin{array}{l}12 \cdot 7,76 \\
102\end{array}$ & $\begin{array}{l}25 \cdot 4,38 \\
51\end{array}$ & $6 \cdot 35$ \\
\hline $40 \cdot 0$ & $\begin{array}{l}6 \cdot 35,12 \cdot 7, \\
25 \cdot 4,38, \\
51,76,102\end{array}$ & 102 & $\begin{array}{l}12 \cdot 7,25 \cdot 4, \\
38,51\end{array}$ & $6 \cdot 35,76$ \\
\hline $79 \cdot 0$ & $\begin{array}{l}6 \cdot 35,12 \cdot 7, \\
25 \cdot 4,38, \\
51,76,102\end{array}$ & 102 & $\begin{array}{l}6 \cdot 35,12 \cdot 7, \\
25 \cdot 4,38, \\
51\end{array}$ & 76 \\
\hline $129 \cdot 0$ & $\begin{array}{l}6 \cdot 35,12 \cdot 7, \\
25 \cdot 4,38,\end{array}$ & 76,102 & $\begin{array}{l}6 \cdot 35,12 \cdot 7, \\
25 \cdot 4,51\end{array}$ & 76 \\
\hline $189 \cdot 0$ & $51,76,102$ & 102 & & 51,76 \\
\hline
\end{tabular}

The table shows that each gap length investigated showed any one of the three mechanisms, depending on the duration of the wavefront. $12 \cdot 7,25 \cdot 4,38$ and $102 \mathrm{~mm}$ gap lengths did not show mechanism $c$ at all, while the $102 \mathrm{~mm}$ gap length showed only mechanism $a$, for all waveshapes.

Fig. 4 shows the variation of $V_{s}$ as a function of risetime for $25.4 \mathrm{~mm}$ gap length. Fig. 4 also includes the results for negative polarity, and will be discussed in Section 2.2. The general pattern of the plots is a fast decrease in $V_{s}$ as the risetime is increased, reaching the lowest $V_{s}$ at a critical risetime. Beyond the critical risetime, up to a time $t_{m}, V_{s}$ increased again, but at a slower rate. For risetimes longer than $t_{m}, V_{s}$ decreased again. The critical risetimes observed for all gap 
lengths had a definite value, either 16 or $40 \mu \mathrm{s}$. $t_{m}$ was about $80-100 \mu$ s for all gap lengths and pressures.

Fig. 5 shows results for a $25.4 \mathrm{~mm}$ gap in nitrogen, and the behaviour is similar to that in air. Again, the critical risetime is $16 \mu \mathrm{s}$ or $40 \mu \mathrm{s}$, as in the case of air, and the possible significance of this is given in the discussion.

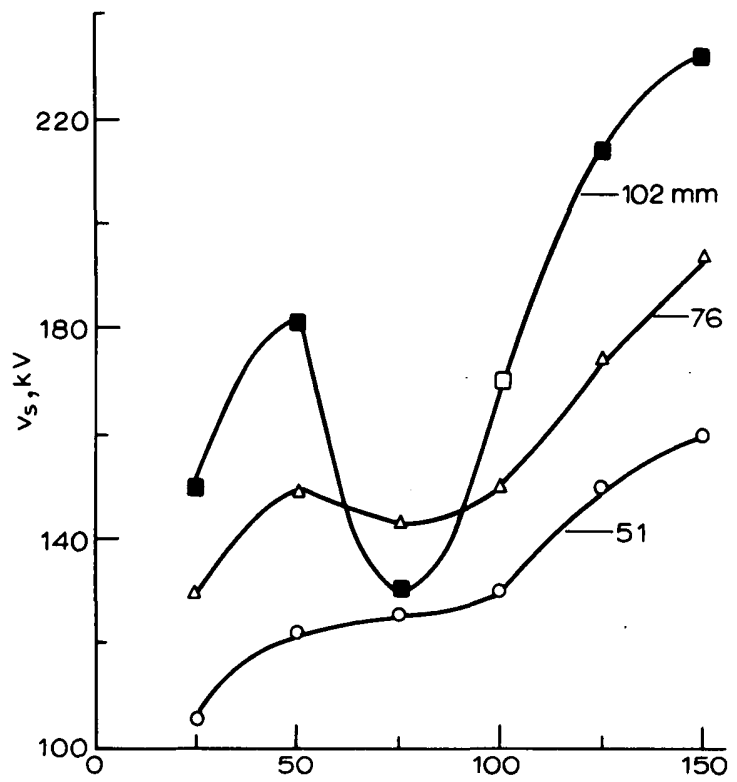

gas pressure $\mathrm{lbf} / \mathrm{in}^{2}$ gauge $\left(704.6 \mathrm{kgf} / \mathrm{m}^{2}\right)$

Fig. 3

$50 \% V_{s} / p$ curves in compressed air at various spacings for $189 / 1100 \mu$ s positive-polarity impulse

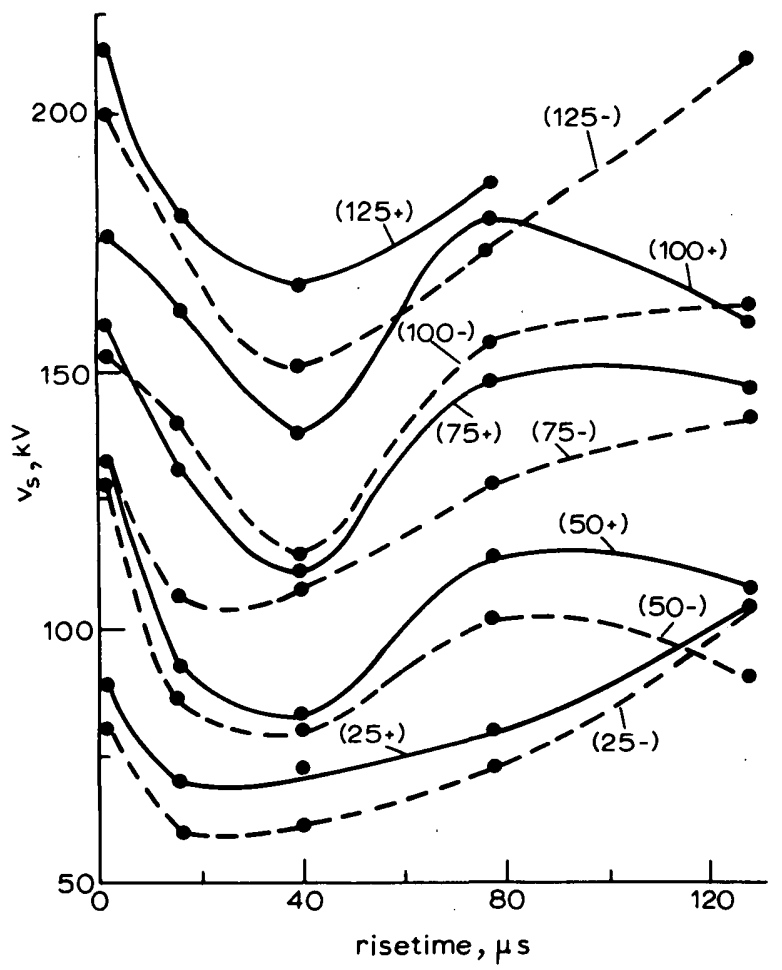

Fig. 4

Influence of impulse risetime on the $50 \% V_{s}$ for a gap spacing of $25.4 \mathrm{~mm}$ in compressed air

Number on each curve denotes gas pressure and polarity

\subsection{Sphere-plane gaps with negative-polarity impuise}

In a previous paper, Govinda Raju et al. ${ }^{8}$ have shown that the $V_{s} / p$ characteristics of a point-plane gap in compressed air showed the critical-pressure effect for a negativepolarity impulse also. The only other gas in which such a behaviour was reported ${ }^{9}$ was $\mathrm{SF}_{6}$, which is also highly electronegative. It was not clear whether the critical-pressure effect for the negative polarity would be observed for a sphere-plane gap, and, therefore, $V_{s} / p$ characteristics were PROC. IEE, Vol. 118, No. 12, DECEMBER 1971 obtained in air for various diameters of high-voltage electrodes and gap spacings. Fig. 6 gives typical results. When the diameter of the high-voltage electrode was $10 \mathrm{~mm}$, no criticalpressure effect was observed for a gap length of $12.7 \mathrm{~mm}$ or lower. When the spacing was increased to $25.4 \mathrm{~mm}$, the critical-pressure effect was pronounced. Similarly, spheres of $20 \mathrm{~mm}$ and $40 \mathrm{~mm}$ diameter exhibited the critical-pressure effect for gaps longer than $38 \mathrm{~mm}$ and $76 \mathrm{~mm}$, respectively. In the case of positive polarity, the critical-pressure effect was not observed for gases which are not electron-attaching. Thus, in nitrogen, hydrogen and argon, Pollock ${ }^{5}$ reported that $V_{s}$ increased with pressure continually, even up to pressures as high as $28 \mathrm{~atm}$. To check whether this was true for the negative polarity also, we measured $V_{s}$ in nitrogen and mixtures of nitrogen and air. Fig. 7 shows that, in pure (commercial cylinder grade) nitrogen, and in nitrogen

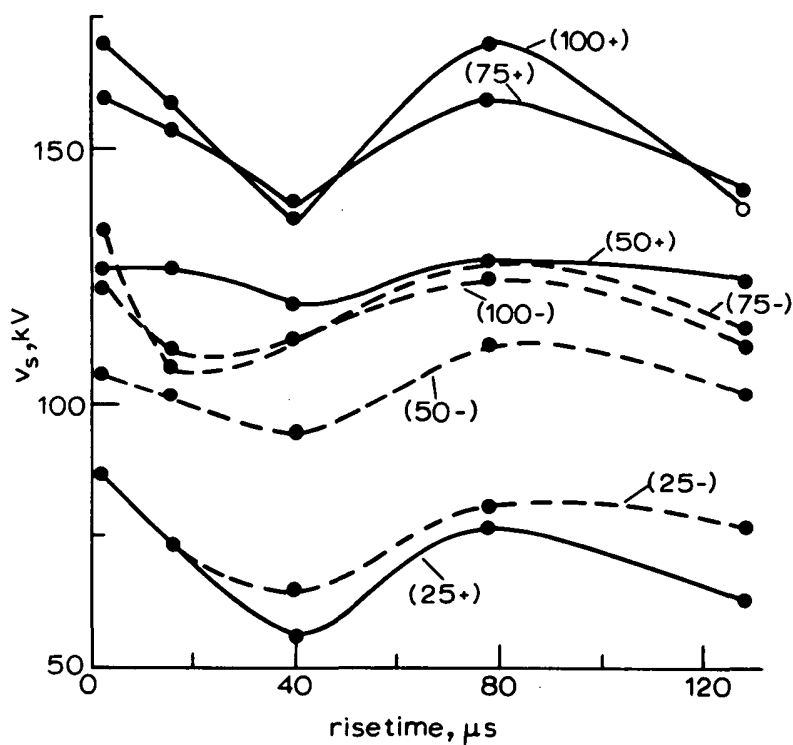

Fig. 5

Influence of impulse risetime on the $50 \% V_{s}$ for a $25.4 \mathrm{~mm}$ gap in compressed nitrogen

Number on each curve denotes gas pressure and polarity

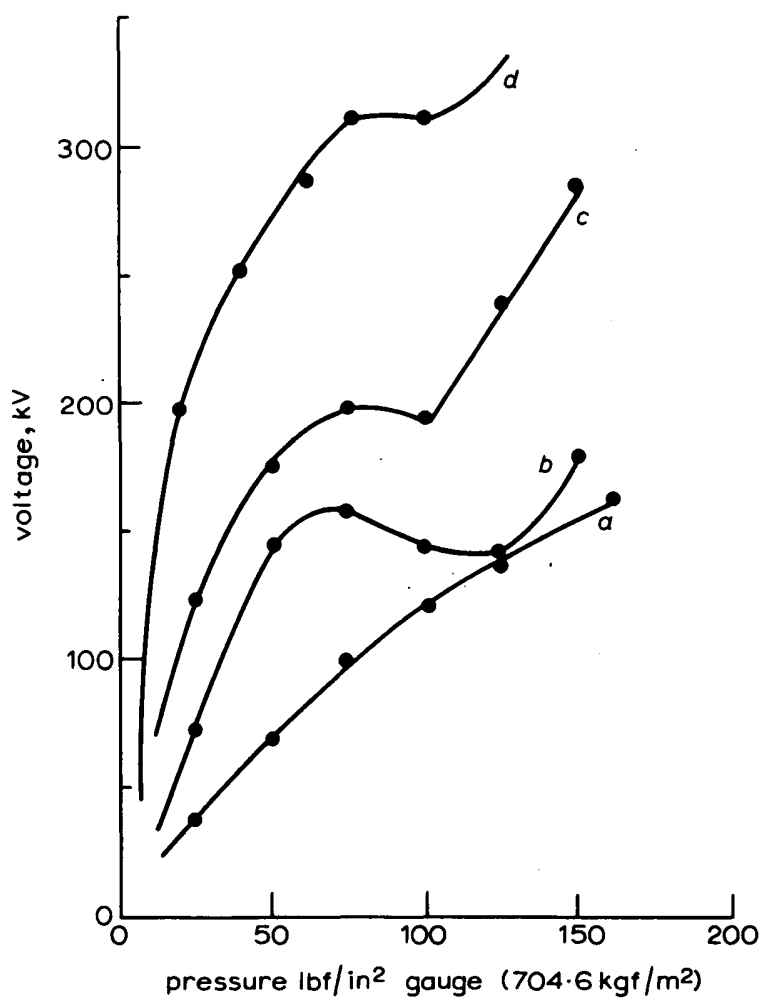

Fig. 6

Breakdown voltage as a function of pressure for various constant electrode radii and spacings for $1 \cdot 2 \times 50 \mu s$ negative impulse voltage 
contaminated with a very small percentage of air, the criticalpressure effect was not observed, even at the highest voltage investigated, but the addition of $50 \%$ air to nitrogen resulted in the critical-pressure effect. It was found that about $5 \%$ oxygen, calculated on the basis of air content, resulted in the peaks in the $V_{s} / p$ curves. The highest breakdown voltage was observed for pure nitrogen, and the lowest for air.

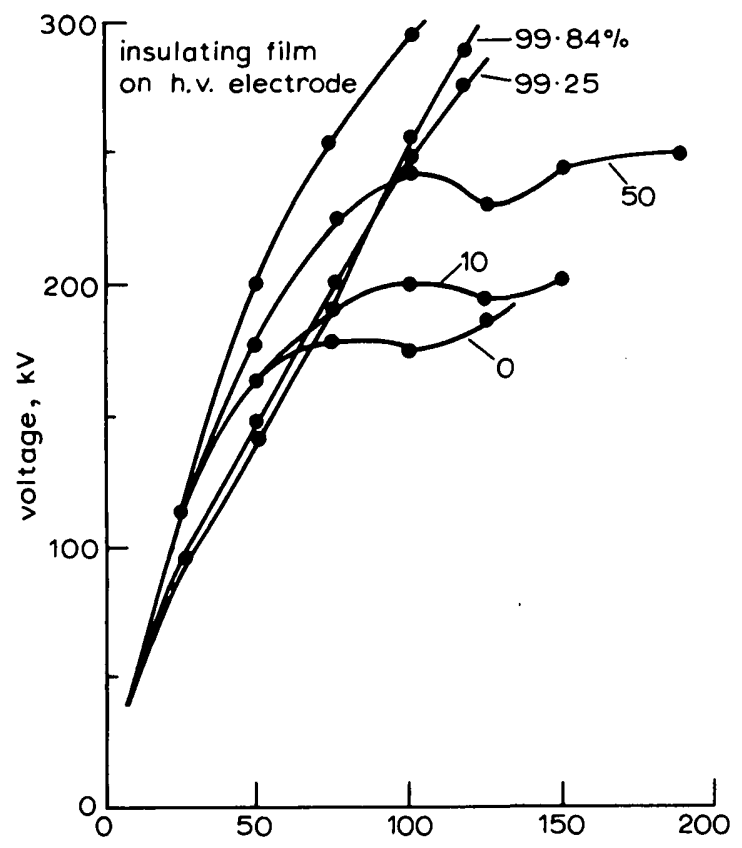

Fig. 7

total pressure $\mathrm{lbf} / \mathrm{in}^{2}$ gauge $\left(704.6 \mathrm{kgf} / \mathrm{m}^{2}\right)$

Breakdown voltage as a function of pressure for air and mixtures of air and nitrogen

$10 \mathrm{~mm}$-diameter electrode, $25 \cdot 4 \mathrm{~mm}$ gap length

For the negative polarity, it is likely that field emission is a major contributing factor for the sudden decrease of $V_{s}$ at pressure $P_{m}$. The field gradient for field emission in a high vacuum with highly degassed electrodes is $10^{6} \mathrm{~V} / \mathrm{cm}$, but Jones et al. ${ }^{11}$ have shown that the threshold may be reduced to $10^{5} \mathrm{~V} / \mathrm{cm}$ if the cathode is oxidised. The electric-field gradient at the sphere was calculated for all the electrode diameters using the formula ${ }^{12}$

$$
E_{y}=\frac{2 \delta\left\{\delta^{2}(f+1)+y^{2}(f-1)\right\}}{\left\{\delta^{2}(f+1)-y^{2}(f-1)\right\}^{2}} V
$$

in which $V=$ applied voltage, $f=\frac{1}{4}\left\{(2 P-1)+\sqrt{ }(2 P-1)^{2}\right.$ $+8\}, P=1+\delta / R, \delta=$ gap length, $R=$ electrode radius and $y$ is the distance along the axis of the gap at which the field is required. The following table shows the field at the sphere at voltages corresponding to a pressure $p_{m}$. Table 2 shows that field emission is a possible mechanism responsible for the critical-pressure effect. To obtain further confirmation, the $V_{s} / p$ curve was obtained for an electrode which was coated with a thin layer of epoxy resin. As expected, the critical-pressure effect disappeared (see Fig. 7). An experimental difficulty was that the insulating film was ruptured after a few impulses, and, for the next impulse, $V_{s}$ was unusually lower, because breakdown occurred at a point where the film was ruptured. This necessitated the frequent renewal of the film. In spite of this uncertainty, we suggest that the film suppressed field emission, and, therefore, the criticalpressure effect disappeared.

\section{Table 2}

\begin{tabular}{c|c|c|c|c}
\hline$R$ & $\delta$ & $V$ & $E$ & Gas \\
\cline { 2 - 4 } & $\mathrm{mm}$ & $\mathrm{kV}$ & $\mathrm{V} / \mathrm{cm}$ & \\
5 & 25.4 & 156 & $3.85 \times 10^{5}$ & air \\
10 & 37.0 & 195 & $1.13 \times 10^{5}$ & nitrogen \\
20 & $76 \cdot 0$ & 272 & $1.58 \times 10^{5}$ & air \\
20 & $100 \cdot 0$ & 220 & $2.54 \times 10^{6}$ & SF $_{6}^{9}$ \\
\hline
\end{tabular}

Figs. 4 and 5 also show the influence of impulse risetime on the negative breakdown voltage in air and nitrogen, respectively. The behaviour is similar to that under positive polarity, but, surprisingly, $V_{s}$, for negative-polarity voltages in air with longer risetimes, is lower than that for positive polarity (Fig. 4).

\section{Discussion}

The breakdown of compressed gases in a nonuniform field has been studied by several workers, using mainly a steady-state voltage, and the critical-pressure effect is reproducible. It is important to note that the critical-pressure effect is not observed in a nonattaching gas or when the electric field in the gap is uniform. Berg and Works ${ }^{13}$ have shown, by an interesting experiment, that the critical-pressure behaviour in electron-attaching gases can be explained on the basis of a mechanism known as 'corona stabilisation'. The breakdown voltage of a sphere-plane gap was measured by superimposing an impulse voltage on a steady-state bias voltage. It was observed that the breakdown voltage, which was the sum of the two voltages, increased with increasing bias voltage. It was suggested that the corona which was formed before the application of the impulse voltage modified and reduced the nonuniformity of the electric field, thereby increasing the total voltage required to cause breakdown. Since a steady-state voltage was used as a bias, it was not possible to determine the time required for the build up of space charge of a density sufficient to modify the electric field. The present investigation shows that, for a given gap, the critical-pressure effect is observed for certain risetimes only, while for other risetimes the voltages increased rather uniformly with pressure. We suggest that this behaviour is consistent with the theory which postulates the modification of the electric field by the space charge, and the criticalpressure effect disappears when the nonuniformity of the field in the gap is reduced because of the drift of charge carriers. A possible explanation for the variation of $V_{s}$ with impulse risetime in air has been given by Boylett et al., ${ }^{14}$ and we suggest that a similar mechanism explains the behaviour of gaps in compressed gases. According to this model, the usual mechanism is obtained at small risetimes. An electron occurring within a certain distance of the point causes the initiation of an electron avalanche towards the point. This will lead to secondary avalanches, and corona filaments are built up until the electric field is too weak to allow further avalanche propagation. It was suggested that, for a filament to propagate across the entire gap, the applied voltage has a unique value. The speed with which the position of the boundary of the limiting field for avalanche propagation moves away from the point is governed by the risetime of the impulse voltage. Depending upon the risetime, four conditions are obtained.

(a) Short-risetime impulse: in this case, the minimum field $E_{c}$ in which an avalanche can propagate moves very rapidly away from the point. For breakdown to occur, an applied voltage is needed of such a magnitude that a field of at least $E_{c}$ is produced everywhere in the gap. Consequently, a high $V_{s}$ is obtained.

(b) Medium-risetime impulses corresponding to the minimumbreakdown voltage: for certain slower risetimes, there will be time for space-charge fields to form because of ionisation produced in the avalanche. If the positive space charge drifts across the gap at the same rate as the rise of voltage, the field due to the applied voltage will always be enhanced by the space-charge field. Thus, the field $E_{c}$ can be produced by a smaller applied voltage, under these conditions rather than in the absence of space charge. The breakdown voltage will be less than in case $a$. The positive-ion space charge drifts across the gap in times of the order of $10-50 \mu \mathrm{s}$, and the risetime at which the minimum $V_{s}$ is obtained is of the same order of magnitude. The variation of $V_{s}$ with risetime was identical both for.compressed nitrogen and air, providing support to the theory that positive-ion space charge influenced the $V_{s}$ risetime curves.

(c) Long-risetime pulses: in this case, the space-charge field will drift away from the point faster than $E_{c}$. Hence, the spacecharge field will reduce the electrostatic field, and hence 
quench the discharge. Consequently, a higher applied voltage is needed to cause breakdown than in case $b$.

(d) In addition, our results show that a maximum $V_{s}$ is obtained at a particular risetime, beyond which $V_{s}$ decreased again. At these very long risetimes, we suggest that the positive-ion space charge traverses the gap completely, and, therefore, the applied voltage alone would be responsible for production of $E_{c}$ everywhere in the gap. Consequently, $V_{s}$ would be lower for longer risetimes, because more time is available for various ionisation processes. This suggests that the $50 \mathrm{~Hz}$ breakdown voltage is lower than the impulsebreakdown voltage of any risetime, and this has been confirmed experimentally.

\section{Acknowledgments}

The authors wish to thank Prof. H. V. Gopalkrishna for providing facilities for this work and for his kind interest. The paper is based on the M.E. project report of K. Natarajan (1969).

\section{References}

1 MEEK, J. M., and CRAGGS, J. D.: 'Electrical breakdown in gases' (Clarendon, 1953)

2 COOKSON, A. H.: 'Electrical breakdown for uniform fields in compressed gases', Proc. IEE, 1970, 117, (1), pp. 269-280
3 - MCCONNELL, Q. Q.: 'Impulse breakdown of compressed air', Elec. Eng., 1957, 76, pp. 984-987

4 CROUCH, K. E., and WHITMAN, L. C.: 'The effect of waveshape on the electric breakdown of nitrogen', IEEE Trans., 1967, EI-00, pp. $1-5$

5 POLLOCK, H. C., and COOPER, F. S.: 'The effect of pressure on the positive point-to-plane discharge in $\mathrm{N}_{2}, \mathrm{O}_{2}, \mathrm{CO}_{2}, \mathrm{SO}_{2}, \mathrm{SF}_{6}$, $\mathrm{CCl}_{2} \mathrm{~F}_{2}, \mathrm{~A}$, He and $\mathrm{H}_{2}$, Phys. Rev., 1939, 56, pp. 170-175,

6 FOORD, T. R.: 'Positive point-to-plane spark breakdown of compressed gases', Nature, 1950, 166, pp. 688-689

7 HOWARD, P. R.: 'Insulation properties of compressed electronegative gases', Proc. IEE, 1957, 104A, pp. 123-138

8 GOVINDA RAJU, G. R., and LAKSHMinARASIMHA, C. s.: 'Negativeimpulse breakdown in compressed air', Electron. Lett., 1967, 3, pp. 460-461

9 STEINIGER, E.: 'Durchschlagverhalten von Schwefelhexafluorid bei Gleich-, Wechsel- und Stoss-spannungsbeanspruchüng', Elektrotech. $Z ., 1965,86$, pp. 583-594

10 LAKShMinaRASIMHA, c. S., and govinda RaJU, G. R.: 'Switching surge breakdown in compressed air' in 'Progress in overhead lines surge breakdown in compressed air' in 'Progress in overhead lines
and cables for $220 \mathrm{kV}$ and above', IEE Conf. Publ. 44, 1968, pp. 102-106

11 LLEWELlyn JONes, F., DE la PARELle, E. T., and MORGaN, C. G.: 'Le rôle des électrodes dans le mécanisme d'amorçage de la décharge électrique dans les gaz', Compt. Rend., 1951, 232, pp. 716-718

12 PEEK, F. W., JUN.: 'Dielectric phenomena in high voltage engineering' (McGraw-Hill, 1929), p. 28

13 BERG, D., and WORKS, C. N.: 'Effect of space charge on electric breakdown of sulphur hexafluoride in nonuniform fields', Trans. Am. Inst. Elec. Eng., 1958, 77, Pt. III, pp. 820-823

14 BOYLETT, F. A. O., EDWARDS, H. G. J., and WILliams, B. G.: 'Variation BOYLETT, F. A. O., EDWARDS, H. G. J., and WILLIAMS, B. G.: 'Variation
of breakdown voltage of a positive-point/plane gap with applied voltage waveshape', Nature, 1965, 207, pp. 1085-1086 